\title{
INTERSECCIONALIDADE, EDUCAÇÃO E REPRESENTATIVIDADE: O IMPACTO DE RAÇA E GÊNERO NO PERCURSO ACADÊMICO
}

\author{
INTERSECTIONALITY, EDUCATION AND REPRESENTATIVITY: THE IMPACT OF RACE AND \\ GENDER ON THE ACADEMIC PATH
}

https://orcid.org/0000-0003-0308-8557 Rosangela Aparecida Hilário A https://orcid.org/0000-0002-0645-8595 Vinicius de Souza Santos ${ }^{B}$

${ }^{\text {A }}$ Universidade Federal de Rondônia (UNIR), Porto Velho, RO, Brasil

${ }^{\text {B }}$ Universidade Federal de Rondônia (UNIR), Porto Velho, RO, Brasil

\section{Resumo}

Este texto é parte de uma pesquisa que objetiva compreender como ser mulher, preta e pobre impacta o percurso acadêmico. Foi estruturado nos conceitos de decolonialidade e Interseccionalidade em Gonzalez (2020), Vergé (2020), Cesaire (2020) hooks $(2017 ; 2019)$ e Carneiro (2019), tendo por questão norteadora como o meio, o espaço lugar afeta e interfere nas normativas para ingresso, permanência e visibilidade na Academia. As análises foram pautadas nas narrativas de uma professora preta, em seu percurso de estudante à protagonista da fundação da Universidade Federal de Rondônia, como única mulher titulada do estado. Como resultados, até o momento, verificou-se serem as avenidas identitárias sinalizadoras de que mulher preta dificilmente alcança espaços de gestão e decisão na Academia.

Palavras-chave: Interseccionalidade; Decolonialidade; Mulher Preta.

\begin{abstract}
This text is part of a research aimed at understanding how being a woman, black and poor impacts the academic path. It was structured in the concepts of decolonility and intersectionality in Gonzalez (2020), Vergé (2020), Cesaire (2020) hooks (2016) and Carneiro (2019), having as a guiding question as the medium, the place space affects and interferes in the norms for admission, permanence, and visibility in the academy. The analyzes were based on the narratives of a black professor, in her career as the protagonist of the foundation of the Federal University of Rondônia, as the only woman with a degree in the state. As a result, so far, it has been found that the identity avenues signal that black women hardly reach management and decision-making spaces in the academy.
\end{abstract}

Keywords: Intersectionality; Decoloniality; Black woman. 


\section{Seguindo o trajeto do Oceano Atlântico: o despertar}

Se as mulheres representam mais da metade da população, as negras representam mais da metade das mulheres brasileiras, e seus problemas são muito maiores que o das brancas. No entanto, aqui, foi tocado timidamente o problema da mulher negra e garanto que, para estarem presentes neste auditório, muitas de vocês deixaram uma negra cuidando dos filhos ou na beirada do fogão.

Abdias Nascimento

Ao analisarmos as vivências e as experiências que nos fazem quem somos e nos mostram o quê, como e onde podemos ressignificá-las, nos deparamos com uma bagagem de histórias que fortalecem e reconfiguram esse percurso de modificação de ideias, perspectivas, posicionamentos e argumentos, em relação à existência e resistência do povo preto, temática a que vimos nos dedicando nos últimos três anos em nossos estudos e pesquisas.

Trazer as memórias de nossas e nossos ancestrais pretas e pretos, como referência para explicar e explicitar as lutas que o povo preto tem enfrentado e travado, é mais do que necessário para que possamos entender o significado do percurso de "diáspora" - forçada e sem consentimento - as marcas no trajeto dos navios negreiros no Oceano Atlântico (AKOTIRENE, 2019) e o reflexo destas marcas e percursos na trajetória e ascensão na Academia.

Memórias são muito mais do que simples histórias contadas para entreter, elas são carregadas de sabedoria, dor, experiência, de significados e sentidos que tendem a despertar naqueles que as escutam o interesse no aprofundamento do reconhecimento de sua existência. Esse texto vem apresentar como as marcas da ancestralidade tem nos motivado a ascender para termos mais que visibilidade na Academia para alcançar espaços de decisão permitindo que tenhamos voz e vez: sermos corpos pretos que ocupam e reclamam trajetória não vividas e ausências que nos marcam, destroem e apequenam. Não nos é possível mais esperar: é preciso promover um resgate na memória e na história para apropriação da cidadania plena, constantemente negada.

A colonialidade consolidou o mito do sujeito universal que explora, mata, saqueia, estupra, escraviza e silencia pessoas, culturas e vozes em nome da expansão geográfica e da ampliação econômica para monarcas e seus cúmplices. O movimento de "colonização" de quem não pediu para ser colonizado e nem coisificado em nome da mitologia cristã, para além de uma hipocrisia manipuladora e de conveniência, se perpetuou ao longo de muitos séculos e tem como substituto na contemporaneidade o neoliberalismo, que busca espaços territoriais fragilizados pelo colonialismo para aumentar lucros e perpetuar dominação: O "humanismo" 
do sujeito universal (leia-se homem, branco e heterossexual) não é destinado a todos os corpos: somente a seus iguais

Aonde quero chegar? A esta ideia: que ninguém coloniza inocentemente, que ninguém coloniza impunemente; que uma nação colonizadora, uma nação que justifica a colonização - portanto a força - já é uma civilização doente, uma civilização moralmente atingida que, irresistivelmente, de consequência em consequência, de negação em negação, chama seu Hitler, quero dizer seu castigo. Colonização: uma cabeça de ponte, em uma civilização. Da barbárie que a qualquer momento, pode levar à pura e simples negação da civilização. (CÉSAIRE, 2019, p. 21)

Ao determinar para quem direitos serão transmitidos, de geração para geração como privilégios, pelo simples fato de nascer com a cor "certa" para ser identificado como sujeito universal, a colonialidade performou e impôs com o regime de terror, comportamentos e nomenclaturas que partem de uma visão segmentada de mundo e o divide entre sujeitos de direitos e privilégios e os que devem se conformar com a vida possível e sem escolhas do outro. Os corpos de mulheres pretas são penalizados em uma sobreposição de opressões que não lhes permite ascender socialmente para além dos espaços de subalternidade. E, se por alguma “concessão" de um estado racista e machista, uma ou outra consegue vencer o silenciamento e a subalternidade, continua solitária e sem voz nos espaços: a solidão da mulher preta está para além do romantismo de não ter um/a parceiro/a para o amor.

Aquelas de nós que estão fora do círculo do que a sociedade julga como mulheres
aceitáveis, aquelas de nós forjadas nos cadinhos da diferença - aquelas de nós que são
pobres, que são lésbicas, que são negras, que são mais velhas - sabem que a
sobrevivência não é uma habilidade acadêmica. É aprender a estar só, a ser impopular
e às vezes hostilizada, e a unir forças com outras que também se identifiquem como
estando de fora das estruturas vigentes para definir e buscar um mundo em que todas
possamos florescer. Pois as ferramentas do senhor nunca derrubarão a casa grande.
Ela pode possibilitar que os vençamos em seu próprio jogo durante certo tempo, mas,
nunca permitirão que provoquemos uma mudança autêntica. (LORDE, 2019, p. 137)

A Academia não foi feita para mulheres pretas. As normas, as metodologias, a apropriação das narrativas utilizadas nas pesquisas seguem a lógica colonial. Os autores citados, as pesquisas reconhecidas e os cargos da burocracia acadêmica têm "perfis" conhecidos. Mas, o feminismo negro tem impulsionado lutas e alimentado a resistência. Estamos chegando, ocupando, produzindo a partir da escuta das mulheres que estão na periferia resistindo a partir dos fundamentos do matriarcado africano, transgredindo, subvertendo e existindo:

No curso de graduação, a sala de aula se tornou um objeto de ódio, mas era um lugar onde eu lutava para reivindicar e conservar o direito de ser uma pensadora independente. A Universidade e a sala de aula começaram a parecer mais com uma prisão, um lugar de castigo e reclusão, e não de promessa e possibilidade. Escrevi meu primeiro livro enquanto fazia o curso de graduação, embora ele só tenha sido publicado anos depois.

[...] Para reagir a essa tensão e ao tédio e apatia onipresentes que tomavam conta das aulas, eu imaginava modos pelos quais o ensino e a experiência de aprendizado 
poderiam ser diferentes. Quando descobri a obra do pensador brasileiro Paulo Freire, meu primeiro contato com a pedagogia crítica: encontrei nele um mentor e um guia, alguém que entendia que o aprendizado poderia ser libertador. (hooks, 2017, p. 1315)

As experiências das meninas pretas nas instituições escolares são uma sucessão de silenciamentos e apagamentos: não fazem parte do time das garotas populares por não se adequarem à estética padrão, não são noivas de quadrilhas de festas juninas, não recebem abraços, não carregam a bolsa das professoras, não são convidadas às apresentações nas festas escolares, não estão nos livros didáticos, nem como parte da história e nem como representantes fundamentais na organização da cultura brasileira. Para caber nos espaços que lhes são destinados e ratificados pela divisão do trabalho escolar (mulheres pretas estão fazendo na escola as atividades que as brancas não querem fazer: limpando banheiros, fazendo e servindo comidas, se ocupando de zelar pela segurança nas brincadeiras) e pela estética do padrão. Se não houve nenhuma paquita preta, não houve também, até onde se tem conhecimento, nenhuma Miss ou Feira das Nações Pretas nas escolas: o Continente Africano, na lógica colonial, não é importante o suficiente para figurar entre as nações que merecem uma festa entre as "colônias".

Mas, referenciadas por Lélia González (2020) na perspectiva de ultrapassar "as limitações de caráter territorial, linguístico e ideológico, que abre novas possibilidades para um entendimento mais profundo dessa parte do mundo onde ela, a amefricanidade, se manifesta" (p. 348 - grifo nosso), permitimo-nos deixar evidenciado a utilização do termo povo preto ao referir-nos a ancestralidade que estará presente neste texto.

[...] justifico também as escolhas pelo "pretoguês" me recuso a me identificar de acordo com as regras e semântica opressoras da linguística racista e eurocentrada: sou preta. Negra é como me definem os manuais do colonizador, a partir de sua métrica e desejo de ser/estar para cima da periferia do mundo. (HILÁRIO, 2019, p. 48)

Transbordar de cor e sentido ao que falamos e escrevemos é mais do que simples movimentos de mudança, é sentir o impacto do que as epistemologias pretas têm realizado dentro e fora de nós. Parece simples, mas requer passar por processos para identificação das dores e pontos de início e continuidade para fortalecer nossas ascensões nos mínimos detalhes.

Tendo como ponto de continuidade (a partida foi nascermos pretos e pobres em uma sociedade que tem como representação do "sujeito universal" o homem branco) as narrativas de uma professora preta que teve papel fundamental para a estruturação da Universidade Federal de Rondônia: a professora Eunice Johnson.

Segundo Carla Akotirene, a história do povo preto é constantemente confundida com uma história baseada apenas no sofrimento, dor e escravidão e, de tal maneira, que as 
resistências acabam sendo esquecidas na tentativa de apagá-las com o movimento das águas (AKOTIRENE; 2019). Reestruturar estas ideias, vivências e resistências é um processo delicado que precisa ser analisado passo a passo pelo estudo da Interseccionalidade que nos permite "enxergar a colisão das estruturas, e a interação simultânea das avenidas identitárias" (AKOTIRENE, 2019, p. 19).

Para que se consiga interpretar o que vivências significam, recorremos aos estudos interseccionais formulados por Kimberlé Crenshawn e ressignificados pelas feministas negras como Davis (2019), Nascimento (2016), Gonzales (2020), Lorde (2019) e hooks (2017), principalmente, que se aprofundam em categorias que não são hierarquizadas, mas que estão operando de forma simultânea sobre a mulher preta.

A reflexão e a assimilação dos acontecimentos nas políticas públicas para a inclusão de pessoas pretas no Ensino Superior precisa ser feita e entendida a partir da compreensão que os postulados direcionados pela colonialidade do pensamento resistem forte às tentativas de enfraquecê-lo para fazer com que desapareçam: a busca de reparação encontra, entre os próprios cientistas, um movimento de boicote e resistência espelhado na "boa intenção" de não enfraquecer currículos e formações, e que não se iniciaram hoje, mas se fundiram na cultura e nas perspectivas geradas pelas estruturas do racismo articulada a um pensamento atrasado em compadrio com o colonialismo:

Seria preciso, antes, estudar como a colonização funciona para descivilizar o
colonizador, para brutalizá-lo no sentido apropriado da palavra, degradá-lo, despertá-
lo para instintos soterrados, cobiça, violência, ódio racial, relativismo moral, e mostrar
que toda vez que no Vietnã há uma cabeça decepada e um olho perfurado, e na França
se aceita isso, uma menina é estuprada e na França se aceita isso, um malgarxe
torturado e a França aceita isso, há um acréscimo de peso morto na civilização, ocorre
uma regressão universal, uma gangrena se instala, um foco de infecção se espalha, e
que no final de todos esses tratados violados, todas essas mentiras propagadas, todas
essas expedições punitivas toleradas, todos aqueles prisioneiros amarrados e
"interrogados", todos esses patriotas torturados, no final desse orgulho racial
estimulado, dessa jactância propagada, existe o veneno incutido nas veias da Europa,
e o processo lento, mas seguro, do asselvajamento do continente. (CĖSAIRE, 2020,
p. 17)

Esse texto é sobre essas veias abertas e sem cura; foi organizado a partir de vivências, experiências, narrativas etnográficas e autoetnográficas, leituras e aprofundamentos nos estudos interseccionais e decoloniais, formulados pelo aquilombamento de ideias, estudos e pesquisas sobre o povo preto por meio das memórias, nem sempre suaves e agradáveis, de uma Professora Preta, acadêmica, titulada e referência de toda uma geração que nunca ocupou um espaço de poder na Universidade Federal de Rondônia, muito embora seu título de Mestra, tenha sido essencial para a organização da instituição: Professora Eunice Johnson. Mas, em função do espaço delimitado para apresentação de nossos argumentos, se materializa também 
na mistura de narrativas possíveis pela autoetnografia: histórias de mulheres pretas em busca de assunção dos espaços de poder são, em grande medida, um misto de resistência, resiliência e esperança. Logo, estamos autorizadas a mesclar narrativas para produzir essa reflexão.

\title{
Tecendo resistências: compreendendo os objetivos
}

Mover-se em disparate a algo é necessariamente um processo de "desacomodação" daquilo que performamos como pensamento mutável. A estrutura da Academia contemporânea não-generalizada, e aqui abarco ela em todas as suas características, desde a oportunidade de acesso que é oferecida a quem recorre aos estudos realizados nela até ao tripé da Universidade (Ensino, Pesquisa e Extensão), é totalmente formulada, ainda, pela perspectiva cisheteropatriarcal, racista e cisnormativa.

As discussões das feministas negras a partir da Interseccionalidade são direcionadas a desacomodar as nossas opiniões para que tenhamos senso de percepções e compreensões dos movimentos e das estruturas que regem e articulam as produções de desigualdade de oportunidades nos processos de ascensão das mulheres pretas, dos povos tradicionais, das dissidências sexuais e das diferentes formas de performatizações de existência, ou seja:

\begin{abstract}
Inicialmente, nos movimentos feministas, mulheres brancas com alto nível de educação e origem na classe trabalhadora eram mais visíveis do que mulheres negras de todas as classes. Elas eram minoria dentro dos movimentos, mas a voz da experiência era a delas. Elas conheciam melhor do que suas companheiras com privilégios de classe, de qualquer raça, os custos da resistência à dominação de raça. classe e gênero. Elas sabiam o que significava lutar para mudar a situação econômica de alguém. Havia conflito entre elas e suas companheiras privilegiadas sobre comportamento apropriado, sobre questões que seriam apresentadas como preocupações feministas fundamentais. (hooks, 2019. P.67)
\end{abstract}

A Universidade, sobretudo a pública, na proposição de uma epistemologia estruturada a partir das bases do colonialismo europeu, definiu as normas e regras para acesso e assunção.

Se para as mulheres brancas e de classe média já era difícil ter assento junto à mesa de debates sobre as ciências, os corpos que se enquadravam em uma estética para além dos “padrões" não eram bem vistos: não por acaso praticamente todas as intelectuais importantes que pautaram uma agenda para o feminismo negro tiveram seu momento de tornar-se uma mulher preta: abrir mão do alisamento dos cabelos, incorporar o turbante e seus significados para a resistência, romper com escritas e teóricos que não consideravam o fato de que para a mulher preta, antes da equidade de salários e de cargos nas profissões mais desejadas, está o direito à existência, as escolhas do que ser e do que não ser. $\mathrm{O}$ feminismo enquanto movimento social não incluía as mulheres que ficavam limpando as casas, cuidando das crianças e preparando o jantar dos maridos das feministas brancas. 
Em Rondônia, a Professora Eunice Johnson, professora, mãe, esposa e ligada aos movimentos das igrejas protestantes progressistas, já havia percebido que falar duas línguas além do português, ser formada em filosofia pura, pesquisar a institucionalização da escola em Rondônia e a formação de professoras para aquele espaço territorial não seria suficiente para ocupar cargos que lhe permitisse compor com outras mulheres como ela.

Nos diálogos estabelecidos ao longo da convivência, primeiro como colega e chefe de departamento, depois como fonte e memória viva para o estabelecimento de uma pesquisa sobre quais estratégias são necessárias para assunção em espaços que possibilitem dar materialidade à máxima "uma sobre e puxa a outra", ela sempre reiterou a importância do fortalecimento de jovens estudantes pretos com o conhecimento de sua história, desenvolvimento do sentido de pertença e autonomia econômica: de nada adiantava ser teoricamente livre e economicamente dependente.

Segundo a Professora Johnson (2019), "Não se olha a nenhum ser humano de cima, por isso dinheiro de menos faz com que estejamos servis e demais desenvolve a arrogância que permite o entendimento de posse sobre corpos, pensamentos e de tudo que importa: conhecimento, cultura, memória, história." No entendimento aqui transcrito, fica evidenciado que o processo de coisificação de pessoas é fortalecido por relações assimétricas pautadas na força e na priorização do capital em detrimento de pessoas.

Em Rondônia, o povo preto não chegou como escravizado, mas sim como operários especializados para contribuir na construção da estrada de ferro Madeira Mamoré, povoamento e desenvolvimento do estado. Porém, na hierarquia dos trabalhos mais reconhecidos socialmente e da assunção a postos de gestão e liderança não houve espaço para as intelectuais, médicas, engenheiros, políticos pretos e pretas.

A cidade de Porto Velho, intelectual, afetiva e organicamente ligada aos caribenhos, não teve um único prefeito ou político de destaque preto e muito menos, mulher preta. Mesmo assim, em 1982, quando foi procurada pelos "acadêmicos" que tinham intenção de perfilar uma instituição de Ensino Superior, a Professora Eunice Johnson aceitou o desafio de fincar a pedra fundamental.

Há de se considerar que naquele momento era a única que podia por possuir um título acadêmico conquistado na Universidade Federal do Rio de Janeiro: Mestra em Psicologia da Educação.

Esse foi o ponto de partida da investigação: como o fato de ser preta e mulher interferiu na assunção da professora na divisão de espaços de poder para reivindicar acesso para outras mulheres pretas? Como o perverso sistema de meritocracia age no espaço da Universidade 
Pública? A Academia tem cor e gênero? Partindo de pontos diferentes é possível atingir/alcançar os mesmos espaços?

Os Estudos Interseccionais nos permitem transitar e reconhecer as vias de opressões e de que forma elas operam sobre o processo de ascensão da mulher preta, dos pretos, das insurgências e dissidências sexuais. E não seria plausível identificar estas opressões de forma ordenada e somada, pelo contrário. Evidenciamos a pertinência do pensamento de Audre Lorde (2019): não há hierarquia de opressões, o sofrimento provocado pela articulação de racismo e sexismo não é maior ou menor naquele ou naquela. É sofrimento que alcança e dói de maneira diferente, mas, que não permite hierarquizar. A dor machuca, silencia, adoece e mata.

Não existem hierarquias quando se trata de se sentir os efeitos das ausências, do imobilismo que leva à subalternização, na conformidade com a existência por falta de tecnologia que alimente a resistência. Desta maneira, mulheres pretas têm vivido à margem e continuam ocupando os últimos lugares em quaisquer estatísticas que se faça para mapear ocupação de espaço de poder e os primeiros lugares na subalternidade.

Por esse motivo, neste estudo a escolha foi analisar as narrativas de uma Professora Preta, ocupante dos espaços de poder que lhes foram permitidos e sobrevivente de toda a rede que se entrepõe na carreira, vivência e resistência das mulheres pretas em articulação, ponto e contraponto com as lutas das meninas pretas que buscam espaço para acessar espaço, esta forma de usarmos as mesmas palavras é justamente assim disposta, para demonstrar os não acessos que precisam ser rompidos na perspectiva de uma possível entrada, desta forma:

\footnotetext{
Aquelas entre nós que estão fora do círculo do que a sociedade julga como mulheres aceitáveis, aquelas de nós forjadas nos cadinhos da diferença - aquelas de nós que são pobres, que são lésbicas, que são negras, que são mais velhas, sabem que a sobrevivência não é uma habilidade acadêmica. É aprender a estar só, a ser impopular e até hostilizada, e a unir forças com outras que também se identifiquem como estando de fora das estruturas vigentes para definir e buscar um mundo em que todas possamos florescer. Pois as ferramentas do senhor nunca derrubarão a casa grande. Elas podem possibilitar que os vençamos em seu próprio jogo durante certo tempo, mas, nunca permitirão que provoquemos uma mudança autêntica. (LORDE, 2019, p. 137)
}

As meninas pretas, em grande medida, carregam desde muito cedo a responsabilidade que a intersecção raça, gênero e classe social lhes facultam sobre os ombros: para essas meninas ser criança e sonhar com um futuro escolhido é um luxo que não podem se permitir. Precisam ficar menores para caber nos espaços destinados na escola, nas relações afetivas e profissionais, na resistência para sobrevivência. É fato que, desde o 14 de maio mal resolvido e sem nenhum planejamento, coube à mulher preta zelar por sua família, pelos mais velhos e pelas crianças. Não fomos convidadas a entrar nos novos tempos como cidadãs. Parece que a ideia era manter mulheres pretas como servas remuneradas sem incluí-las nos debates para a emancipação 
sexual e reconhecimento do potencial intelectual e profissional, até porque a pauta destas mulheres estava muito além da liberdade sexual, a posse sobre seus corpos, seus desejos e sua existência. Mesmo que falassem inglês e, entre uma tarefa e outra, aperfeiçoassem sua leitura e ampliassem sua interpretação sobre o mundo e seu lugar/espaço, não eram bem vindas nas discussões e reflexões:

\begin{abstract}
Grande parte da história ocidental europeia nos condiciona a ver as diferenças humanas como oposições simplistas: dominante/subordinado, bom/mau, em cima/embaixo, superior/inferior. Em uma sociedade em que o bom é definido em relação ao lucro, e não as necessidades humanas, deve sempre existir um grupo de pessoas que mediante a opressão sistemática, pode ser levado a se sentir dispensável, ocupando o lugar do inferior desumanizado. Nessa sociedade, esse grupo de pessoas é formado por pessoas negras e do Terceiro Mundo, pela classe trabalhadora, pelos idosos e pelas mulheres. (LORDE, 2019, p. 141)
\end{abstract}

Por esse motivo, analisamos como se manifestam as opressões que se estruturam e se naturalizam no ambiente acadêmico, tendo em primeiro plano as memórias e narrativas de uma professora preta com os atributos apresentados como importantes para assunção e permanência na Academia e, mesmo assim, relegada ao papel de coadjuvante, ainda que tenha "emprestado" seu título para que as tratativas ocorressem,

Analisamos não apenas o racismo que ali operou, mas também o sexismo. Ou seja, entrecruzou-se não apenas a questão de raça como uma unidade apenas, mas percebe-se que junto a este fato também operam outras matrizes de opressões, e que são estas que acabam sendo refletidas no percurso de muitos pretos e principalmente da mulher preta (OLIVEIRA, 2017).

A partir do entendimento ampliado sobre o significado destes movimentos do Oceano Atlântico com a carga de suor, lágrimas, desesperança e sofrimento, que veio junto ao povo preto, visualizamos como as matrizes das opressões estão a todo momento operando não para imobilizar, mas para a derrocada do povo preto em sua emancipação. Não podemos esquecer que "a diáspora negra deu suor, lágrimas e sangue ao gosto do Mar" (AKOTIRENE, 2019, p. 42). Logo, é a necessidade de que essas matrizes de opressão sejam desmontadas que impulsionam a luta por um mundo mais equânime de afetos, conhecimentos e vidas múltiplas.

Junto às análises feitas a partir do estudo da Interseccionalidade, analisamos também as questões relativas à Academia - Legislações para a política de inclusão e permanência da população preta na Universidade - aspectos que ainda são realizados de maneira pouco visível e que tornam-se efetivos para o processo de exclusão e inserção de pessoas pretas, LGBTQIA+ e mulheres pretas na estruturação de quem deve e quem não deve participar da Universidade. 
A abordagem da pesquisa é qualitativa, do tipo de pesquisa descritiva, com fase bibliográfica e documental, e de campo (entrevista com a Professora Eunice Johnson) com suas respectivas técnicas e instrumentos, à luz de autores estudados na área educacional, de raça e sexo-gênero. Os métodos de procedimentos foram: levantamento bibliográfico, análise documental, entrevistas, aplicação e análise conclusiva à luz dos estudos teóricos efetuados. Foi realizada no período de agosto de 2019 a junho de 2020.

Para o objetivo proposto a este estudo, a pesquisa de cunho qualitativo apresentou-se como a melhor alternativa metodológica, visto que é empregada quando se deseja conhecer "as perspectivas dos participantes, em suas práticas do dia a dia e em seu conhecimento cotidiano relativo à questão em estudo", partindo-se da "noção da construção social das realidades em estudo" (FLICK, 2009a, p. 16). Entende-se, também, que a presente pesquisa é um estudo de tipo exploratório, tendo como objetivo "proporcionar maior familiaridade com o problema, com vistas a torná-lo mais explícito" (GIL, 2002 p. 41).

A metodologia utilizada para a execução deste trabalho se deu em quatro etapas: a primeira etapa baseou-se nas pesquisas realizadas em obras para a compreensão do conceito que foi determinante para as percepções dos marcadores sociais que operam sobre a população preta e sobre as dissidências sexuais. Sendo estes conceitos o conceito de Interseccionalidade, decolonialidade e Autoetnografia crítica.

A Interseccionalidade diz respeito às interações das avenidas identitárias e como essas interações chocam-se e afetam quem se encontra no meio dessa avenida - os pretos, a mulher preta, a população LGBTQIA+, as Culturas Indígenas, e outras demarcações que são submetidas ao processo de invisibilidade e subalternização - nos possibilitando perceber que não há diferenciação de opressão, são todas opressões baseadas em três marcadores, a raça, o gênero e a classe social (AKOTIRENE, 2019).

Por meio da Interseccionalidade é que compreenderemos que os movimentos que se fazem para excluir e apagar as memórias do povo preto, que estão sendo utilizadas como base para ascensão dos pretos e pretas na Academia, são movimentos que se estruturam por conta dos privilégios que não são disponibilizados a todos como direitos, e da herança escravocrata que ainda é refletida na contemporaneidade.

Junto a este conceito, desafiamo-nos a compreender o significado destas memórias, que são, em sua grande maioria, contadas apenas oralmente. Para isso, foi necessário entendermos o conceito de Autoetnografia crítica que "oferece subsídios teórico-metodológicos fundamentais à investigação, ao produzir sentidos sobre o espaço e as relações estudadas.” (CAETANO; JÚNIOR; TEIXEIRA, 2020, p. 39) 
A compreensão do que a Autoetnografia crítica significava se dava por conta da parte documental e de campo da pesquisa, visto que foram feitas entrevistas com a Professora Eunice Johnson narrando experiências que são significativas para a compreensão do objetivo desta pesquisa: a análise dos aspectos de raça e gênero na ascensão da mulher preta na Academia.

Por fim, mas não menos importante, no campo teórico, debruçamo-nos sobre os pressupostos dos fundamentos da decolonialidade por meio das intelectuais negras, como hooks (2019), LORDE (2019) e CARNEIRO (2019), que analisam e avaliam de que forma os processos de colonização atrelados a expropriação, devastação e aniquilamento dos territórios invadidos incidiu e incide sobre a organização da cultura, da história e das práticas escolares e acadêmicas.

A segunda etapa consistiu nas entrevistas que foram realizadas com a professora Eunice Johnson com o intuito de ouvir narrativas que impulsionassem a compreensão de como o acesso da Professora Eunice Johnson foi mitigado na medida em que a Universidade se expandia e chegavam as professoras brancas do sul e sudeste que ocuparam os espaços de poder e decisão acadêmicos.

A terceira etapa consistiu em um excerto das narrativas coletadas no decorrer da pesquisa, em função das limitações de espaço, tendo como diretriz e provocação as realidades vivenciadas para que sua presença inspirasse outras e outros, ainda que não estivesse ocupando cargos e funções na gestão administrativa na Universidade.

Por fim, passaremos a analisar e debater, no próximo subtítulo, a pasta atrás do armário, a importância da memória e da história ancestrais como estratégia para o combate a colonização do pensamento, que apaga história e silencia memória. Nosso entendimento até aqui é o de que as vozes da resistência para existência da mulher preta pautaram e encorajaram não só a trajetória da Professora Eunice Johnson, mas de outras e outros que vieram após ela e se orientaram por seus passos e se beneficiaram dos avanços conquistados por sua resiliência.

\section{A pasta atrás do armário: um percurso traçado pela Interseccionalidade a partir das narrativas de uma mulher preta}

No Brasil, em razão da herança escravagista que durante quase 400 anos "coisificou" pessoas pretas lhes roubando a dignidade, o pertencimento e a identidade social em nome de interesses mercantilistas, o povo preto tem sido submetido a espaços de subalternidades, que perpassam por múltiplas facetas, principalmente a questão econômica, em face da situação de vulnerabilidade e falta de oportunidades. Homens e mulheres sem terras, sem trabalho, sem profissão, sem escolaridade, sem dinheiro e sem esperança, no dia 14 de maio de 1888 foram 
colocados à margem da sociedade sem que, de alguma maneira, o Estado brasileiro se responsabilizasse por tamanha desumanidade.

Em grande medida, em condições precárias, considerando que foram abandonados sem condições mínimas de sobrevivência, nem mesmo a roupa do corpo. Os limites da irresponsabilidade com os herdeiros do caos da escravidão é um estigma que o povo preto carrega, não tendo acesso aos seus direitos plenos à cidadania, ocupando os piores postos de trabalho e tendo a escolaridade mais baixa entre os trabalhadores brasileiros, por exemplo. Considerando que as políticas têm sofrido inúmeros reveses e retrocessos, desde primeiro de janeiro de 2019, a situação tende se agravar.

A relação das maternagens pretas com a instituição escolar tem sido, ao longo do tempo, uma relação permeada de contradições: o processo de resistência implica saber/ensinar a remoer a dor de ser invisível e de ser preterida. É ir até o limite do absurdo para se manter na escola sem se ver nos lugares de destaque: raramente estão nos corpos gestores, nos cargos elevados, no par principal da quadrilha da festa junina, nos concursos de belezas e livros didáticos. São/somos ensinadas a não nos incomodarmos de não sermos escolhidas, mas nos importamos. Quando uma mãe preta vai à escola fazer uma reclamação e defender seu filho/a, ela representa todas as outras e não está defendendo só aos seus, defende a quem é tirado o direito de se fazer ouvir e reclamar injustiças, mas a queixa só acontece no limite.

\footnotetext{
Criar crianças pretas - meninos e meninas - na boca de um dragão racista, machista e suicida é perigoso e arriscado. Se eles não puderam amar e resistir ao mesmo tempo, provavelmente não vão sobreviver. E, para que sobrevivam, precisam se desprender. É isto o que as mães ensinam - amor e sobrevivência -, ou seja, definição de si desprendimento. Para cada uma dessas lições, a capacidade de sentir amor, como não desconsiderar o medo nem ser dominado por ele, como experimentar a alegria de sentir profundamente. (LORDE, 2019, p. 93)
}

Assim, criar uma criança preta é viver sempre entre o limite do amor e da resignação, da contradição entre ensinar a buscar a liberdade e a justiça, e a se manter vivo como maior ato de resistência. Mudaram os sujeitos, a legislação e os contextos, mas não mudaram as normas pedagógicas coloniais que tornam invisíveis toda e qualquer ação, manifestação e cultura que não esteja dentro do "padrão" colonial eurocêntrico, mesmo em um país onde a mestiçagem confunde e desorganiza regras rígidas de raça e racialidade. Contudo, o preto está sempre saldando uma conta que não termina.

A junção de políticas que buscam possibilitar acesso ao povo preto a mais escolaridade, como o sistema de cotas e as alternativas criadas por essas mulheres para prover o sustento de sua família e as políticas de inclusão social levadas a cabo ao longo dos últimos quinze anos, 
tornou perceptível um movimento em relação à assunção a lugares mais elevados da pirâmide social, ainda que tímido.

Para além da problemática racial, encontramos ainda a de gênero, em razão da cultura patriarcal: subvertendo a palavra meritocracia, apresentam a homens e mulheres, sobretudo às pretas, condições desiguais e injustas de desenvolver percursos que valorizem as capacidades individuais e articulem a um projeto/intenções pessoais de desenvolvimento para avanços individuais e coletivos a favor das comunidades, dos bairros e cidades.

São suficientemente conhecidas as condições históricas nas Américas que construíram as relações de coisificação dos negros em geral e das mulheres negras em particular. Sabemos, também, que em todo esse contexto de conquistas e dominação, a apropriação social das mulheres do grupo derrotado é um dos momentos emblemáticos de afirmação de superioridade do vencedor. Hoje, empregadas domésticas de dondocas, ou de mulatas tipo exportação. (CARNEIRO, 2019, p. 314)

A somatização das opressões sistêmicas de classe, gênero e raça, conforme estudado por Angela Davis, torna-se cada vez mais evidente no Brasil, onde de acordo com o IPEA, na pesquisa dos Retratos das Desigualdades de Gênero $4^{\circ}$ Edição, cerca de 4.1 milhões de famílias são chefiadas por mulheres, e mulheres pretas ocupam o terceiro lugar no ranking educacional do país, ficando apenas à frente dos homens negros, contudo elas ocupam a base da pirâmide de pessoas em situação de desemprego.

Essa era uma das grandes ironias do sistema escravagista: por meio da submissão das mulheres a exploração mais cruel possível, exploração esta que não fazia distinção de sexo, criavam-se as bases sobre as quais as mulheres pretas não apenas afirmavam sua condição de igualdade em suas relações sociais, como também expressavam essa igualdade em atos de resistência. Essa deve ter sido uma terrível descoberta para os proprietários de escravos, pois aparentemente eles tentavam quebrar essa cadeia de igualdade por meio da repressão particularmente brutal que reservava às mulheres. (DAVIS, 2016, p. 37)

Refletindo sobre todos esses pontos, houve entendimento ampliado sobre as pesquisas que interpretam o significado para uma mulher preta, em termos dos direitos da mulher e para o combate à discriminação, à violência doméstica e à opressão, mais anos de escolaridade por meio do conhecimento dos direitos e dos caminhos de acesso para fomentar com intervenções individuais ou coletivas.

Compreendemos que o encontro com nossa ancestralidade por meio das narrativas são momentos enriquecedores, que nos mostram a possibilidade de entendermos quem somos, quem fomos e como podemos ressignificar quem seremos. A ancestralidade do povo preto vem repleta de narrativas de silenciamentos, apagamentos histórico-culturais, de apropriação de uma cultura que não pertence a nós, mas em contrapartida a isto, analisamos esta ancestralidade no 
oposto a todos estes aspectos: a resistência para existência. Vemos um povo que traduz o que significa e o que significou resistências, existências e persistências.

Mecanismos que são identificados pela pirâmide social de poder, status e hegemonia e que estão operando a todo momento contra as bases dessa pirâmide para que não haja a inversão pela ascensão. Mecanismos de opressões que há 132 anos estão operando seja pela linguagem, pelas políticas públicas, pela dificuldade de acesso das mulheres a espaços de poder, e no caso das mulheres pretas, nem poder e, menos ainda, voz.

A professora Eunice Johnson foi a grande protagonista deste conhecimento em processo, pois é/foi através das narrativas compartilhadas por ela que se pode fazer uma análise interseccional dos reflexos do processo histórico de silenciamento e repressão sobre a mulher preta na Universidade. Ela é uma mulher preta que teve diversos percalços em sua trajetória de ascensão desde o magistério até sua chegada a Universidade Federal de Rondônia. Exemplo de mulher resistente e inspiração de outras tantas mulheres pretas que se espelham nela para conquistar e trazer outras mulheres pretas para os espaços de conhecimento.

Esta afirmação pode ser observada quando analisamos uma entre as narrativas com que fomos instados a refletir sobre como essas manifestações interseccionais de preconceito e apartheid ocorrem nos corredores institucionais: perguntada sobre como se deu a resistência para os enfrentamentos para sua permanência na Academia, a Professora Eunice Johnson não titubeou, seu corpo escuro, sendo político, era mais do que um símbolo de resistência, era uma bandeira fincada para inspirar a nova geração a permanecer. Primeiro resistir e permanecer na escola de Educação Básica, tendo que provar sempre que se merece e tem direitos para estar presente nas instituições. Depois, buscando acesso nas instituições de Ensino Superior e, por fìm, acessando funções e cargos na gestão acadêmica.

A filósofa feminista preta Angela Davis (2018) afirma que "quando uma mulher negra se movimenta, toda a estrutura da sociedade se movimenta com ela". Estar na Universidade e ser representatividade para alguém, segundo a professora Eunice, era dar a possibilidade de "espelhagem" que traduz resistências e possibilidade de ascensão.

Trazendo novamente à memória o movimento do Oceano Atlântico percebemos que o início do processo de escravidão dá-se na retirada do povo negro de sua terra, no percurso no Oceano Atlântico, até a herança escravocrata que hoje ainda se apresenta e se reformula. Esse processo de ascensão em busca pela liberdade que se concretiza todos os dias, aparece nas narrativas da professora Eunice Johnson: 
Eu sempre quis aprimorar meus conhecimentos e meus títulos, mas quando abriam vagas para fazer doutorado sempre foi uma dificuldade pra eu conseguir entrar, o que não acontecia por exemplo com minhas outras companheiras brancas do departamento em que eu efetivamente exercia minha função. Lembro que eram inúmeras as explicações de desculpa que se utilizavam, mas a que me marcou muito foi quando me disseram que eu não iria fazer meu doutorado, pois sequer haviam enviado minha documentação e que a minha pasta havia caído atrás do armário. (Eunice Johnson, 2019)

Esta narrativa foi fundamental para que compreendêssemos os processos de exclusão que operavam, e que, infelizmente, ainda operam na Universidade, nas escolas, nas vivências de meninas pretas e das insurgências. O contexto de reflexão baseia-se em uma suposta negligência de uma pasta que desaparece. Entre todas as pastas que poderiam desaparecer, justamente a que continha documentos de uma mulher preta, que ia buscar seu título de doutora, essencial para acesso aos cargos que possibilitam, de certa forma, a tomada de decisões, foi a que foi perdida fazendo com que ela deixasse de concorrer a um processo seletivo de doutorado e ficasse para trás na disputa pelo reconhecimento e assunção aos cargos e funções da gestão institucional. O fato é que a pasta foi localizada atrás do armário, quando não havia mais possibilidade de consertar as coisas. Eram outros tempos, segundo a própria professora.

A Academia segue em seus temas e em suas discussões que não contemplam as epistemologias do Sul: os questionamentos que eram (são) feitos por uma Universidade no norte do país, em meio aos processos de expropriação e destruição das riquezas da floresta, do genocídio nos territórios quilombolas população por meio da ineficiência e descaso da política pública para acesso à escola, e do não reconhecimento das diferenças identitárias e culturais dos povos da floresta, se dão em meio à leitura de autores, teóricos e pesquisadores europeus, não para referenciar ao fenômeno, para analisar e buscar respostas.

Sendo contextos diferentes, provoca frustração e distanciamento, fazendo com que os pesquisadores professores se acostumem com a nomeação de "Universidade periférica" sem estofo para entendimento da complexidade de viver e conviver em meio a um território em disputa: currículo e narrativas. Segundo Djamila Ribeiro "se não se nomeia uma realidade, sequer serão pensadas melhorias para uma realidade que se é invisível” (2017, p. 41). A realidade aqui apresentada é uma realidade de silenciamento, invisibilidade e de reinserção das categorias interseccionais: gênero e raça para o entendimento da falta de mobilidade nos percursos de ascensão do povo preto na Academia.

O racismo se aloja em um território necessário de interpelação pela luz da existência, confrontando o discurso de igualdade racial existente, precisamos pensar melhorias para o fim dessas problemáticas, a partir delas, por isso é relevante o conceito de Dororidade, levantado 
por Vilma Piedade (2019), que traduz uma dor que foi/é sentida apenas por uma categoria de pessoa: a mulher preta.

Mas, voltando um pouco a história pelas narrativas da professora Eunice Johnson, vamos observar que, desde sua entrada na Universidade, os recortes de raça e gênero estavam presentes. Na organização e estruturação da Universidade Federal de Rondônia, era necessário um quantitativo de pessoas capacitadas e habilitadas para participarem da criação dela. Como na época eram poucas as pessoas que possuíam título acadêmico na cidade de Porto Velho, a procura por alguém com aptidão titulada e capaz de comprová-las foi constante e, a única pessoa que podia e estava apta a este feito, na época, era a Professora Eunice Johnson.

O que devemos destacar são dois pontos: o primeiro que o título que poucas pessoas possuíam e a professora já tinha foi essencial para legitimar e organizar a criação da Universidade Federal de Rondônia, e o segundo, como ela narrou: o título só foi utilizado para estruturarem a Universidade, mas nas legitimações das honrarias e divisão de cargos, seu nome e sua presença foram descartados.

Quando esta alcança um lugar de status na Universidade, o cargo de chefe de Departamento, são grandes as realizações feitas por ela, mas a que quero trazer à memória diz respeito a outra professora preta, que passa pelo mesmo percurso de ascensão e pelas mesmas dificuldades, mas que recebe o apoio da professora Eunice Johnson, vejamos a seguinte narrativa:

\footnotetext{
Quando ela quis fazer doutorado, aproveitar a oportunidade que havia surgido, foram muitas as desavenças por parte dos colegas, que na maioria eram brancos, para que ela ficasse e continuasse a ministrar suas aulas, mas como eu sabia que era muito importante adquirir esta titularização a impulsionei e briguei literalmente com o departamento a quem era chefe para que ela fosse e fizesse seu doutorado e foi o que aconteceu. (Eunice Johnson, 2019)
}

A narrativa apresenta um momento em que a autoridade da Professora Eunice Johnson, em posição de destaque e decisão na instituição, foi essencial para que uma professora preta, migrante e pobre pudesse cursar seu doutorado, já que o departamento formado por professoras brancas que evocavam as entrelinhas da legislação para exigir que a colega (recém-chegada) ao departamento tivesse que escolher entre sua sobrevivência ou a continuidade do curso de doutorado. A professora não só definiu que ela teria as duas coisas como assumiu as aulas da referida professora para que ela pudesse cursar as últimas disciplinas e viver o processo de formação inerente ao doutorado. Idosa, com duas disciplinas no curso, assumiu mais três disciplinas e a colega pode seguir em frente. Ao se doutorar um ano e meio depois, dedicou o título a Professora Eunice Johnson, que foi impedida de conquistar ao seu próprio. 
Ser mulher e preta na Universidade ainda é um desafio constante, pois as marcas das opressões sociais refletem e agridem com força esse percurso. Racismos, opressões de gênero, silenciamentos dentre outros são aspectos que permeiam a ascensão da mulher preta na Universidade, potencializando a solidão que é enfrentada pela maioria das mulheres pretas. Por isso "a Interseccionalidade nos mostra como e quando mulheres pretas são discriminadas e estão mais vezes posicionadas em avenidas identitárias, que farão delas vulneráveis à colisão das estruturas e fluxos modernos." (AKOTIRENE, 2019, p. 63)

A professora Eunice Johnson trouxe suas memórias à baila com uma potencialização muito grande para identificarmos os marcadores sociais, podemos começar pela falta de textos, pesquisas e/ou homenagem que destacassem sua importância para a fundação da única Universidade pública do estado de Rondônia. Então, além de apresentar dados empíricos sobre as dificuldades de ascensão da mulher preta na Academia, esse texto se propõe ao reconhecimento de quem veio antes: honrar a ancestralidade é resgatar memórias e fazer delas um impulsionador a encorajar e fortalecer na busca de um mundo onde todas as pessoas caibam em meio as suas diferenças.

\section{Ancestralidade, ascensão e análise: marcadores sociais presentes na trajetória acadêmica}

Confrontar perspectivas que levam alguém a determinado lugar é, sobretudo, um movimento de resistência. O percurso de ascensão de determinados indivíduos, quando observados pela perspectiva interseccional, será traçado a partir das colisões estruturais que chocam a existência deste sujeito. Reintegrar e reviver memórias são métodos de pesquisa que nos possibilitam uma compreensão mais objetiva de como operam os mecanismos de opressões nos percursos de todos aqueles que fogem a regra universal.

Trazer à tona as narrativas de pessoas que a todo momento foram colocadas como última opção é ouvir vozes que sempre estiveram ecoando. Pelas narrativas da professora Eunice Johnson, e analisando o contexto contemporâneo, vamos identificar que antes de se colocarem ascensões serão apresentados os processos de exclusão, de invisibilidade, de silenciamento, de apagamento histórico.

Pensar que os percursos de ascensão acadêmica são moldados por estruturas identitárias e por mecanismos de opressões nos faz perceber que nós trazemos em nossas raízes históricasculturais padrões, que influenciam diretamente em nossas escolhas, ascensões, vivências e posicionamentos. 
Pelas narrativas da Professora Eunice Johnson, percebemos aspectos essenciais para o entendimento de como operam os marcadores sociais de raça, gênero e classe: por meio da Interseccionalidade, notaremos que o percurso da professora foi marcado pelos estereótipos (raça) e pela classe que a professora ocupava (classe social). O choque destas estruturas revela quem está no meio delas. Seria então relevante pensar que uma proposta de compreensão deva basear-se não apenas na influência das categorias de raça, gênero e classe social na vida acadêmica, mas em que estas categorias irão encontrar-se de maneira mais palatável.

A estrutura social, se analisada pela perspectiva de decolonização e interseccional, é formulada pela exclusão de determinados indivíduos. Seria simples e direto sugerir que os indivíduos excluídos seriam os pobres, mas cabe a nós, enquanto pesquisadores, aprofundarmos o entendimento sobre os mecanismos de exclusão para desvelar suas estratégias para operar.

Pensar isto é se apropriar do pensamento reflexivo e provocador de Carla Akotirene no que tange às pessoas brancas, que se utilizam de ancestralidades negras distantes para justificarem sua entrada na Universidade por meio da Política de Cotas Raciais. "A identidade branca desmascara quem se passa por negro sem sê-lo, dando as chances políticas de ser branco de verdade." (AKOTIRENE, 2019, p. 47) e ainda:

Quando se fala branco se está falando para além da cor da pele, até devido a fluidez e contingência da experiência de "brancura" - a mesma pessoa é identificada de modo diferenciado em regiões diferentes, pois para a Europa, entretanto, só é branco o branco europeu. (AKOTIRENE, 2019, p. 47)

As políticas de reparação dão suporte a uma herança que não nos foi dada desde o dia 14 de maio de 1888. Respeitá-las é uma atitude que permite às pessoas que há muito tempo passaram por processos de tentativa desumanização sejam contempladas em seus direitos e que a efetivação deles ocorra. O uso inadequado para tentar fraudar estas políticas é algo desumano, que permeia a manutenção de uma determinada classe e raça no topo da sociedade do conhecimento.

Pensar que diálogos pautados em desculpas, e em levantamento de barreiras, para que as pessoas que fogem do padrão europeu do sujeito universal perdurem até os dias de hoje por meio, por exemplo, de se fraudar o sistema de cotas, do enfraquecimento da Educação Básica Pública, da retirada da laicidade do estado, que se pauta na ética das religiões cristãs (dogmas) para definir os rumos de política pública, pela dificuldade de acesso as mulheres de maneira geral, e as pretas em particular, para acessar os equipamentos e conhecimento que vai lhes permitir transitar com segurança e proficiência na Academia; todas essas são estratégias repetidas que se interrelacionam para dificultar acesso. A cada obstáculo ultrapassado, é criado mais um que arremessa mais à frente a linha de chegada. 
Podemos exemplificar com a análise da revogação da Portaria de 11 de maio de 2016, que reconhece direito a acesso aos cursos de pós-graduação por meio do uso de cotas a pessoas pretas. Essa revogação não só exemplifica o movimento das avenidas identitárias, como nos mostra quem está no meio destas avenidas. Ou seja, seletivamente, nos aponta quem deve e quem não deve estar lá.

Essa revogação, proposta por um ministro de estado com fulcro em entrelinhas, e que por pressão popular não se efetivou, seria então o dedo indicador apontado para a porta da rua, ou seja, significa que quem é contemplado por esta portaria um dia estava lá, mas não deveria estar, segundo as mentes formadas pelo pensamento colonizador: conhecimento emancipa, faz com que procuremos a efetivação plena de direitos.

Estas ações e atitudes não partem de agora e vêm imbricadas no movimento histórico das pessoas que fogem do perfil normativo. Pensarmos negritudes significa pensarmos também branquitudes e como elas são parte do processo de exclusão e acesso do povo preto às Universidades.

Pensarmos as questões de ascensão das populações LGBTQIA+ na Academia significa pensarmos também de maneira interseccional, ou seja, uma pessoa que se identifica sendo bicha, que é autodeclarada preta, estará no meio das colisões estruturais da sociedade, interpelase pela visão interseccional analisar como estas colisões atingiram e dificultaram o processo de ascensão deste indivíduo, sendo feito a intersecção de raça, gênero, sexualidade e classe social, para percebermos que o racismo também operará junto com o silenciamento, de narrativas potencializadoras, pela homofobia (OLIVEIRA, 2017, p. 93).

A Interseccionalidade nos instrumentaliza para que vejamos estes detalhes e não os consideremos como simples vivências e narrativas. É por meio delas que vemos os assujeitamentos que acontecem no processo de ascensão social dos pretos, da mulher preta e dos/das LGBTQIA+, desde o primeiro contato com o ambiente de ensino formal. Um exemplo seria pensarmos este processo de assujeitar pela perspectiva proposta por Marcio Caetano quando diz que "os e as estudantes cujos gêneros, sexualidades e corporalidades estão em desacordo às normas dominantes estão sujeitos a violentos mecanismos de assujeitamentos." (CAETANO; LIMA; CASTRO, 2019, p. 11).

Potencializar os estudos interseccionais nas Universidades é também uma atitude de acesso porque demarca a universalização do acesso real a todos, mas não apenas na inserção destes nela, e sim no permanecer deles até a formação integral de seu conhecimento e emancipação de suas capacidades de autonomia e ascensão. 
Possibilitar que essas discussões possuam/explicitem o significado da dor, da exclusão e da visibilidade que tanto foi mencionado por estes estudos é possibilitar que o profissional que exerce ou exercerá a docência tenha sensibilidade para trabalhar e perceber o outro com um olhar de empatia, que revele uma escola com respeito e com capacidade de performar a real existência de dignidade, respeito e afetividades múltiplas.

\section{Conclusão: negritando o debate}

O início deste percurso foi, sem dúvida, arrebatador. Transpormos as barreiras do racismo tem sido um desafio diário e que precisa de instrumentos e tecnologia para fazer a resistência e permitir as novas gerações se libertarem dos estigmas que acompanham a vida da mulher preta que ousa se insurgir contra a vida de subalternidades e apagamentos determinado para sua existência. A Interseccionalidade nos instrumentalizou para a compreensão de como os marcadores sociais e as avenidas identitárias se estruturam.

Os resultados encontrados nos apontam que a Universidade Pública, ainda, infelizmente, é, e parece ter sido sempre, moldada a partir da perspectiva cisheteropatriarcal branca, racista e seletiva, e que a ascensão da mulher preta na Universidade ainda é dificultada em função de uma perspectiva colonial de aprendizagem e do que pode ou não ser validado pelos cânones da Academia. Para isso, recorremos à narrativa da Professora Eunice Johnson, mulher preta, que trouxe aspectos que, ainda, são reflexos de uma estrutura excludente, e que permitem-nos ter uma visão interseccional de como operam os marcadores sociais, na ascensão de mulheres pretas em relação à população branca.

As narrativas potencializam estas compreensões e não são simples palavras ao vento, são memórias resgatadas, são o direito a fala daquela que nunca teve o protagonismo. O racismo se intersecciona com a classe social e influencia na ascensão de muitas pretas que estão em processo de emancipação na Universidade.

Diante destes aspectos, conclui-se que precisamos falar de Ascensão e de Mulher preta na Universidade e trazer estas discussões para a Formação Docente, permitindo que as muitas vozes sejam escutadas e tenham equivalência aos estudos e status que devem ter, para além dos muros da Universidade. É preciso ressignificar este pensamento de desordem, que diz que estas discussões só podem ser feitas por quem é preto ou preta. Essa discussão é de todos, a sociedade é múltipla e cabe a nós, enquanto pesquisadores, confrontar as narrativas hegemônicas e apresentar versões que desafiem a história única contada pelos vencedores de uma guerra injusta. 
Concluindo essa reflexão vale retomar algumas das indagações que orientaram a coleta de dados para a pesquisa e a reflexão que se organizou a posteriori: já temos uma Reitora Preta na Universidade, mas sua presença não está refletida nem na divisão de cargos entre mulheres e homens e nem na assunção de pesquisadores e pesquisadoras pretas a cargo de direção e liderança. Os professores e as professoras pretas continuam sendo ponto de referência em seus respectivos departamentos: em uma "brincadeira" que traduz a perversão do pensamento colonial, se diz nos departamentos que a cota já foi cumprida.

Refletir sobre como as pontuações a respeito de "brincadeiras" vêm refletidas desde a entrada da professora Eunice Johnson, ainda que a Universidade fosse estruturada tendo como ponto fundamental a titulação que só ela detinha no momento, apresenta os reflexos da exclusão e da não visibilidade destes corpos na Universidade. Mesmo na contemporaneidade, tendo em vista o percentual de pesquisas desenvolvidas envolvendo estas reflexões na Universidade: em um universo de 176 pesquisas envolvendo a temática no Mestrado Acadêmico em Educação, apenas oito abordavam temas relacionados a raça, representatividade e política de reparação ${ }^{\text {iii }}$. Ser cota em um espaço excludente é ser, além de resistência, alvo e, sendo alvo, toda repressão decai sobre si.

$\mathrm{Na}$ Universidade, as pessoas pretas estão nos cursos menos procurados, nos trabalhos que ninguém gosta de executar, nas funções invisíveis: faxineiras, copeiras, serviçais. As funções valorizadas pela Academia têm cor e gênero sim: branca e homens. As intempéries de um percurso desigual não permitem que todos e todas possam acessar espaços. Todo o esforço da Professora Eunice Johnson nunca foi reconhecido pela Universidade, muito pelo contrário: na edição e nos festejos do trigésimo aniversário, ela não foi nem convidada e nem citada em nenhuma das publicações feitas na época. Foi apagada da história da Universidade e da memória dos seus estudantes.

Mas, algumas mulheres pretas têm estourado os cadeados limitadores do racismo e do sexismo que "emparedam" a ascensão e assunção na carreira e revertido o conceito de Interseccionalidade a favor das pautas da mulher preta: a juventude preta, recém-chegada aos bancos da Universidade, após 500 anos de abusos e ausências, não parece disposta a abrir mão de suas conquistas. Inspiradas e fortalecidas pelo exemplo da Mestra Eunice Johnson, suas pautas e estudos com referência dos fundamentos do Matriarcado Africano, tem fortalecido e honrado a ancestralidade com a máxima de que "uma sobe e puxa a outra". 


\section{Referências}

AKOTIRENE, Carla. Interseccionalidade. (Feminismos Plurais) São Paulo: Sueli Carneiro; Pólen, 2019.

CAETANO, Márcio.; LIMA, Carlos Henrique Lucas.; CASTRO, Amanda Motta.

Diversidade sexual, gênero e sexualidades: temas importantes à educação democrática. In Colloquium Humanarum, Presidente Prudente, v. 16, n. 3, p. 5-16 jul./set. 2019. Disponível em: https://revistas.unoeste.br/index.php/ch/article/view/3179

CAETANO, Márcio Rodrigo Vale.; TEIXEIRA, Tarciso Manfrenatti de Souza.; SILVA JUNIOR, Paulo Melgaço da. Bichas Pretas E Negões: Seus Fazeres Curriculares Em Escolas Das Periferias In Revista Teias v. 20, n. 59, out. /dez. 2019. Disponível em: https://www.epublicacoes.uerj.br/index.php/revistateias/article/view/44438

CARNEIRO, Sueli. Escritos de uma vida. São Paulo: Pólen, 2019.

CÉSAIRE, Aimmèe. Discurso sobre o colonialismo. São Paulo: Veneta, 2020. 136 p.

DAVIS, Angela. Mulheres, raça e classe. Tradução de Heci Regina. Candiani. 1. ed. São Paulo: Boitempo, 2016.

FLICK, Uwe. Introdução à pesquisa qualitativa. 3. ed. Porto Alegre: Artmed, 2009. 405 p.

GIL, Antônio Carlos. Como elaborar projetos de pesquisa. 4a. ed. São Paulo: Atlas S/A. 2002.

GONZALEZ, Lélia. Por um feminismo afro-latino-americano: ensaios, intervenções e diálogos. / Org.: Flávia Rios, Márcia Lima. 1ª ed. Rio de Janeiro: Zahar, 2020.

HILÁRIO, Rosangela Aparecida. O Feminismo Negro como estratégia para assunção de direitos as Mulheres Pretas e Periféricas. Ensaios filosóficos. Rio de Janeiro. v. 20, p. 40 - 57, dez. 2019.

HOOKS, Bell. O feminismo é para todo mundo: Políticas arrebatadoras. Rosa dos Tempos, 2019. Fontes, 2017.

Ensinando a transgredir: a educação como prática de liberdade. São Paulo: Martins

LORDE, Audre. Irmã Outsider. Ensaios e conferências. Tradução Stephanie Borges. 1. ${ }^{\text {a }}$ ed. Belo Horizonte: Autêntica Editora, 2019.

.Idade, raça, classe e gênero: mulheres redefinindo a diferença. In: Pensamentos feministas: conceitos fundamentais. Org. HOLLANDA, Heloisa. Buarque de. Rio de Janeiro: Bazar do Tempo, 2019.

OLIVEIRA, Megg Rayara Gomes $O$ diabo em forma de gente: (r) existências de gays afeminados, viados e bichas pretas na educação. - Tese de Doutoramento. Curitiba, 2017.

PIEDADE, Vilma. Dororidade. São Paulo: Editora Nós, 2017.

RIBEIRO, Djamila. O que é lugar de fala? Belo Horizonte: Letramento, 2017. (Feminismos Plurais)

VERGÈS, Francoise. Um feminismo decolonial. Tradução Jamille Pinheiro Dias e Raquel Camargo. São Paulo: Ubu Editora, 2020. 144p. 
i Povo de Madagascar, que foi colônia da França até 1960.

ii Pseudônimo da Professora e pesquisadora Glória Jean Watkins.

iii Fonte: Mestrado Acadêmico em Educação/UNIR.

Revista Interinstitucional Artes de Educar. Rio de Janeiro, V.7, N.3 - pág. 1610-1632 set-dez de 2021: "Dossiê Relatos de experiências e produção acadêmica” - DOI: https://doi.org/10.12957/riae.2021.54677 